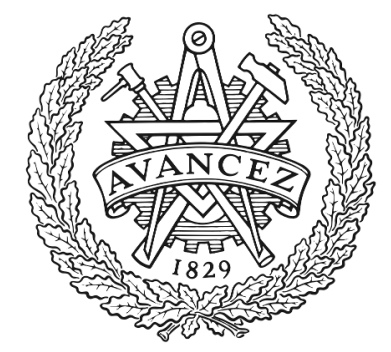

CHALMERS

UNIVERSITY OF TECHNOLOGY

\title{
The Operator 4.0: Towards socially sustainable factories of the future
}

Downloaded from: https://research.chalmers.se, 2023-04-26 15:08 UTC

Citation for the original published paper (version of record):

Romero, D., Stahre, J., Taisch, M. (2020). The Operator 4.0: Towards socially sustainable factories of the future. Computers and Industrial Engineering, 139: 2-5.

http://dx.doi.org/10.1016/j.cie.2019.106128

N.B. When citing this work, cite the original published paper. 
Editorial

\section{The Operator 4.0: Towards socially sustainable factories of the future}

\section{A R T I C L E I N F O}

\section{Keywords:}

Operator 4.0

Work 4.0

Organisation 4.0

Industry 4.0

Factories of the future

Social sustainability

Cyber-physical production systems

Human systems

\begin{abstract}
A B S T R A C T
Humans are all makers of a sort. The tools we operate constantly leverage our human capabilities and evolve over history to take advantage of any innovation or a new source of power that emerges. Human-Technology Symbiosis has always been the basis for leaps in human prosperity. As we are presently in the Fourth Industrial Revolution, or Industry 4.0, it is important to focus on challenges and opportunities of contemporary work-life. Here we find the worker, the operator, benefitting from cyber-physical systems technology, connectivity, and global information networks while retaining human strengths and weaknesses. This special issue will describe the implications of a new breed of the manufacturing worker, "The Operator 4.0". The 13 contributions in this special issue will take us from the early anthropocentric organisational models to the emerging connected and cyber-physically enhanced "Operator 4.0" in highly dynamic work environments. Methods and tools for development and analysis of complex work will support the scholar or practitioner that would like to dig deeper into the future of the potential work-life of the Operator 4.0.
\end{abstract}

\section{Introduction}

Long before the advent of the Internet of Things (IoT) and the emergence of Cyber-Physical Systems (CPSs) for advanced, digital, and smart manufacturing paradigms, the impact of close interaction between humans and machines was projected to radically enhance industrial performance. In 1983, just around the birth of the personal computer, Dr. Peter Brödner proposed the benefits of "Anthropocentric Production Systems", with transparent and self-descriptive design and adjustability to different degrees of user experience or reliability. Implementation was projected to be swift and based on the, at that time new, Computer Integrated Manufacturing (CIM) paradigm in the "Fabrik 2000" (Brödner, 1988a,1988b). Obstacles and workarounds were vividly described by Bainbridge (1983), Stahre (1995), and many others. By the mid-1990s, the harsh reality of complex (Dimirovski et al., 2006), unpredictable manufacturing systems had shattered the contemporary visions and dreams of fully computer-controlled factories where no humans needed to work.

Almost 30 years later, computers look very different, and the Fourth Industrial Revolution is expected to transform our production systems and the industrial workforce (BCG, 2015a). This will have significant implications on the nature of work in the industry as "Industry 4.0 " is transforming the design, engineering, manufacturing, operation, and servicing of products and production systems (BCG, 2015b). Unfortunately, at the same time, the demographics are changing and ageing populations in some countries unhinges additional challenges for manufacturing companies. Consequently, manufacturing enterprises, and in particular 'Smart Factories' as socio-technical systems, will need to form and adapt to a new social perspective to be proficient in assisting ageing, disabled, and apprentice operators. Advanced digital and industrial technologies will help people to remain in, return to, or be incorporated into the modern manufacturing workforce. Meanwhile, developments from a technological perspective, such as new connectivity enablers and interaction technologies among components (cf. smart products), machines (cf. smart machines) and humans (cf. smart operators) will make industrial production systems more lean, integrated, agile, traceable, and adaptable (Romero, Noran, Stahre, Bernus, \& FastBerglund, 2015).

To successfully embrace the Industry 4.0 paradigm in a socially sustainable way, manufacturing enterprises will need to accompany its technological transformations with training and development programs for their workforce. New tools and technologies will be deployed that skilled labour uses and by which the operators are directly and indirectly affected (Romero, Bernus et al., 2016).

New working environments such as 'cyber-physical factories' and 'digital twin environments' will directly influence the operator and the nature of work, creating new interactions not only between humans and machines but also between digital and physical worlds. Therefore, a socio-technical transformation towards the Factory of the Future (cf. Factory 4.0/Smart Factory) will need a new design and engineering philosophy for 'human-centric' and 'cyber-physical' production systems. Automation, robotics, and other advanced manufacturing technologies are seen as enablers for the further enhancement and augmentation of the human's physical, sensorial, and cognitive capabilities rather than for unmanned, autonomous factories (Romero, Bernus et al., 2016; Romero, Stahre et al., 2016).

This special issue identifies and characterizes the early manifestations and future projections of the OPERATOR 4.0, "understood as a smart, skilled operator who performs not only cooperative work with robots but also aided work by machines as and if needed by means of human cyber-physical systems, advanced human-machine interaction technologies and adaptive automation towards achieving human-automation symbiosis work systems" (Romero et al., 2015; Romero, Bernus et al., 2016; Romero, Stahre et al., 2016). Further, to explore 
key enabling technologies, models, and methods, along with design and management techniques and approaches that can support the development of human-automation symbiosis work systems, such as Assembly Systems 4.0 or Smart Assembly Stations (Cohen, Naseraldin, Chaudhuri, \& Pilati, 2019) with real/time collaboration, sharing, trading, monitoring, and control of processes. This could involve the creation of digital twins of physical assembly processes to enable true synergistic interactions between humans and machines and digital and physical worlds.

\section{The special issue papers}

Will it be different this time? Will the technological development of the Fourth Industrial Revolution bridge the gap between "romantic" expectations on technological disruption on one hand, and the harsh reality of complex unpredictable systems on the other hand. The guest editors and contributing authors of this special issue of Computers and Industrial Engineering - Journal on "The Operator 4.0: Towards Socially Sustainable Factories of the Future" reflect on it.

\subsection{Human-centric production systems and its historical perspective}

The opening paper by Rauch et al., titled "Anthropocentric Perspective of Production before and within Industry 4.0", addresses the past, present, and future of human-centred design approach(es) for socially sustainable (cyber-physical) production systems with special emphasis on the interaction between humans and machines. The paper highlights the transformation of human-machine and human-computer systems interactions, induced by the so-called Industry 4.0 technologies, and reflects on the new tasks and roles of human operators in relation to smart machines and computer systems. Furthermore, the paper demonstrates the evolution of human-machine and human-computer systems interfaces from user-interfaces - oriented to programming and control to interactive-interfaces - oriented to collaboration and cognitive, physical and sensorial support of human operators for an improved technical and organisational design, execution and maintenance of for socially sustainable (cyber-physical) production systems (viz., digital factory planning tools, virtual human-centred planning, augmented planning systems, human-robot collaboration, lean automation, supervision and monitoring systems, machine data capturing, intelligent assistance systems, virtual training, advanced decision support systems, etc.) (Rauch, Linder, \& Dallasega, 2019).

\subsection{Work systems analysis and work design}

The paper by Fantini et al., titled "Placing the Operator at the Centre of Industry 4.0 Design: Modelling and Assessing Human Activities within Cyber-Physical Systems", details and addresses the current challenges and needs for modelling and assessing human work in relationship with technological systems in the Factories of the (near) Future (FoF). The research work proposes a methodology for expanding the scope of the analysis and design of human work with the objective of human integration within Cyber-Physical Production Systems (CPPSs), also referred to as Human-in-the-Loop. The proposed methodology supports the design and assessment of different human-systems configurations (viz. collaboration, integration, and symbiosis) in order to orient the design choices for the level of human activity within a CPPS. The paper provides general recommendations and guidelines for work design in the FoF. It encourages managers and engineers to develop a multi-perspective awareness on the role of workers as creative thinkers, decision-makers, and problem-solvers within a CPPS environment where technological systems do not try to replace humans, but assist, augment, or automate part of their work as needed. Moreover, in order to provide human inclusiveness and harness the strengths of human and technological systems, new physical and cognitive tasks allocations methods will need to be developed with the intention of achieving new levels of efficiency and productivity that neither systems can achieve alone in the socially sustainable factory of the future (Fantini, Pizone, \& Taisch, 2018).

\subsection{New manufacturing jobs and urbanisation}

The paper by Matt et al., titled "Urban Production - A Socially Sustainable Factory Concept to Overcome Shortcomings of Qualified Workers in Smart SMEs", profiles the future roles and jobs of workers in a harmonised vision of smart cities and smart 'urban' factories, remarking the recruitment challenges ahead for SMEs when it comes to skilled workers for the Industry 4.0 era. The paper discusses the imminent shortage of qualified workers and provides general measures for building highly attractive urban factories in order to compete for the needed Talent 4.0 (Matt, Orzes, Rauch, \& Dallasega, 2018).

\subsection{Human-centric technology adaptation}

The paper by Kaasinen et al., titled "Empowering and Engaging Industrial Workers with Operator 4.0 Solutions", discusses the need for socially sustainable factories of the (near) future that are perfectly suited for workers with different skills, capabilities and preferences. Such factories should represent a more interesting working environment with greater autonomy and opportunities for self-development. In this paper, workforce empowerment is achieved by adapting the factory shop-floor to the skills, capabilities, and needs of the worker, supporting the worker to understand and to develop his/her competences by means of digital assistance systems and technologies. Moreover, workforce engagement is realized through participatory approaches for the design of the workplace and manufacturing processes. Thus, the socially sustainable factory of the (near) future is called to become a knowledge sharing and adaptive learning environment that supports personalized competence development and learning while human operators are working for the success of the business and its production objectives (Kaasinen et al., 2019).

The paper by Flecther et al., titled "Adaptive Automation Assembly: Identifying System Requirements for Technical Efficiency and Worker Satisfaction", presents a three-component exploratory study that includes (i) a benchmarking review of adaptive technologies (viz. augmented reality, assisted reality, virtual reality, collaborative robots, adaptive/self-learning production control, interactive/adaptive interaction mechanisms, optical control systems, driverless transportation systems, and lifting aids); (ii) an analysis of multidimensional user requirements (viz. organisational level, automation and robotics, communication and interaction mechanisms, system feedback and assistance, and system information and instructions); and (iii) a business case definition of use case scenarios for the development of a new adaptive automation assembly system. The paper provides a set of recommendations on how to build enhanced socio-technical assembly systems that incorporate advanced technologies to augment human-system interaction and performance measures, worker satisfaction, and socioeconomic sustainability (Fletcher et al., 2019).

\subsection{New production roles and personas}

The paper by Pizone et al., titled "A Framework for Operative and Social Sustainability Functionalities in Human-Centric Cyber-Physical Production Systems", conceptualizes a holistic framework to analyse the functionalities of a CPPS with focus on human and operational performance impacts using a hierarchy of technological levels (viz. smart resource, smart resource system, and smart resource system orchestra). Within the holistic framework, CPPS functionalities are defined in 
terms of their objectives and intended outcomes. Such human-centric functionalities and their corresponding technologies, have been named as following in this paper, the Silent Teacher - supporting the operators' individual learning process with the intention of continuously improving their skills and ultimately making the company more competitive (q.v. gamification, virtual reality, augmented reality, mixed reality); Knowledge Manager - handling relevant information flows from different stakeholders with the aim of enabling the 'learning organisation' (q.v. digital twins, big data analytics); Resource Integrator - enabling a more agile, flexible and reconfigurable CPPS that can quickly react to market changes towards the 'resilient factory' (q.v. modularity, plug-\&-produce); Caregiver - minimising the negative impact of certain cognitive and physical tasks that operators perform in order to improve their working environment, and in turn, their performance (q.v. wearables); Risk Manager - reducing all human and equipment risks so as to create a healthier, safer and productive workplace (q.v. conditionbased systems); and Flow Master - managing and improving all materials flows in the CPPS in order to reduce lead times and improve quality (q.v. industrial internet of things, advanced scheduling solutions). The paper contributes to set the stage for identifying different social aspects in manufacturing and determining their interaction with production and operative dimensions towards socially sustainable factories of the future (Pinzone et al., 2019).

\subsection{Collaboration \& gamification}

The paper by Lithoxoidou et al., titled "A Novel Social Gamified Collaboration Platform Enriched with Shop-Floor Data and Feedback for the Improvement of the Productivity, Safety and Engagement in Factories", introduces a gamified social collaboration platform to the shop-floor. It proves that human interaction should exist in the Workplace 4.0 and that it helps in solving daily issues that would take a lot of time otherwise without face-to-face interaction. The platform combines a collaborative environment with game features with the purpose of promoting and supporting the participation of operators in the exchange of concerns, ideas and knowledge. The platform also supports the engagement of operators in their daily jobs by triggering motivation and offering positive feedback. Overall, the social collaboration platform can create a pleasant and friendly work environment where operators can participate in collective activities and improve their team spirit, which directly translates into improved productivity, safety and engagement in the shop-floor (Lithoxoidou et al., 2019).

\subsection{Human-machine interaction and cognitive augmentation}

The paper by Peruzzini et al., titled "Exploring the Potential of Operator 4.0 Interface and Monitoring", proposes the adoption of a human-centred design approach inspired by 'The Operator 4.0' concept (Romero, Stahre, Wuest, Noran, Bernus, Fast-Berglund, \& Gorecky, 2016b) with the aim of demonstrating the feasibility of integrating human factors in the Industry 4.0 computerized industrial frameworks. The approach is based on the collection of data about the operators' performance, actions and reactions, via wearable technologies (e.g. biosensors), with the objective of combing it with the IIoT-enabled smart machines' data with the intention of improving the overall factory performance by means of smart, augmented human-machine interfaces/interactions. Such new interactions will allow avoiding bottlenecks at the shop-floor, optimisation of workflows, and to improve workstations' design and layout in order to build socially sustainable industrial workplaces for enhanced operators' performance, wellbeing, and quality of life within the factories of the future (Peruzzini, Grandi, \& Pellicciari, 2018).

The paper by Mattsson et al., titled "Forming a Cognitive Automation Strategy for Operator 4.0 in Complex Assembly", advocates for a three-step strategy for the design of cognitive automation solutions for the Operator 4.0 (Romero, Bernus et al., 2016) as his/her work tasks expand in CPPSs environments from learning new (assembly) tasks to solving difficult problems and initiating changes. The suggested strategy starts with (i) the selection of assembly phases, (ii) followed by the choice of the level of cognitive automation carrier, and (iii) finalises with the recommended cognitive automation content. The paper highlights the importance of a participatory design approach for the cognitive automation solution, and of support between its implementation phases of Learning new work tasks, routines and toolsusage; Operating within the new working environment; and handling unknown Disruptions (LOP). Furthermore, for each phase different 'knowledge' (viz. skill-based, rule-based, or knowledge-based behaviours) and 'cognitive processes' levels (viz. reasoning and/or intuition) are recommended before proposing the most suitable 'cognitive automation level' (viz. from totally manual to totally automatic) for the work tasks (Mattsson, Fast-Berglund, Li, \& Thorvald, 2018).

\subsection{Human-machine interaction solutions}

The paper by Zolotová et al., titled "Smart and Cognitive Solutions for Operator 4.0: Laboratory H-CPPS Case Studies", describes the evolving roles of operators in production systems and presents a set of laboratory case studies that illustrate the possible applications of smart and cognitive solutions for the Operator 4.0 (Romero, Stahre et al., 2016) in the emerging Human-CPPSs (H-CPPSs). This research is a response to the Industry 4.0 demands for new levels of productivity and effectiveness from the workforce. These laboratory case studies address four different scenarios for the Operator 4.0, from legacy systems to cognitive healthcare to maintenance and prediction to machine2people interactions. The first case study proves how modern Human-Machine Interfaces (HMIs) can improve reaction time of operators, in comparison to legacy screen systems; the second case study demonstrates how wearables can improve the productivity, wellbeing and safety of the workforce; the third case study reveals how a Service Oriented Architecture (SOA)-based production system can provide a full-stack solution for device integration, data acquisition, data processing and remote control to enable operators to always have the right information and the right time at hand for decision-making and/or action-taking; and the fourth case study illustrates how augmented cognitive interactions based on automated visualisation screens can proactively support operators to receive only the relevant information at their smart devices from near-by machines without the need of pushing buttons to pull out a report. $H$-CPPSs call for a 'social factory architecture' enabling an Internet of smart, connected and proactive Things, Services, and People (IoTSP) (Zolotová, Papcun, Kajáti, Miškuf, \& Mocnej, 2018).

\subsection{Advanced visualisations and simulations}

The paper by Segura et al., titled "Visual Computing Technologies to support the Operator 4.0", depicts how visual computing technologies (viz. virtual reality, augmented reality, computer vision, visual analytics, HMI interfaces, digital twins, etc.) can play a key role in empowering operators with digital tools and solutions for improving their decision-making and action-taking processes in CPPSs. The application of visual computing technologies in specific tasks such as assembly, maintenance, quality control, training, inventory and machines operation empowers the operator to better address real industrial problems in Industry 4.0 scenarios. These visual technologies contribute decisively to the enhancement of operators' ability to perform traditional tasks and to easily learn new ones. Moreover, the paper notes that these visual computing technologies do not act in 'isolation', but work in 'connection' with other digital and physical systems of the smart factory environment in order to improve quality and productivity for the socially sustainable factory of the future (Segura et al., 2018). 


\subsection{Ergonomics analysis}

The paper by Bortolini et al., titled "Motion Analysis System (MAS) for Production and Ergonomics Assessment in the Manufacturing Processes", presents an original hardware and software architecture for a Motion Analysis System (MAS) aimed at the human body digitalisation and in-depth analysis and evaluation of the human labour content during the execution of manufacturing and assembly tasks within common industrial workstations. The MAS is based on the integration of motion caption technology with an ad-hoc software developed for 'productive' and 'ergonomic' analysis of the operator during his/her work. The system provides industrial engineers with a valuable tool oriented to support work design considering productive, and ergonomic viewpoints in order to improve a workstation layout, location of tools and components, musculoskeletal workload, etc. towards a highly socially sustainable workplace (Bortolini, Faccio, Gamberi, \& Pilati, 2018).

\subsection{Human as product/service designers and makers}

The last paper of this special issues by Taylor et al., titled "Operator 4.0 or Maker 1.0? Exploring the Implications of Industrie 4.0 for Innovation, Safety and Quality of Work in Small Economies and Enterprises", focuses on unleashing the human creative potential as a complement to the robotic and virtual world of the fully automated cyber-physical production system. The paper foresees the 'Operator 4.0' transition into a 'Maker 1.0' where humans work alongside a CPPS, but only in the role of product designer and engineer, rather than in the role of supervisor of non-discretionary workflow steps or processes in the production. The authors' vision aims to enhance the role of humans as 'makers' and not 'standby operators' for a better quality of working life in the socially sustainable factories of the future (Taylor, Boxall, Chen, Xu, Liew, \& Adeniji, 2018).

\section{Discussion and further reflections}

The Operator 4.0 concept or paradigm - is as much a statement of human capabilities as it is a description of technological enhancements needed to compete with purely technical solutions. This special issue has taken us from early anthropocentric models of human-technology interaction in advanced manufacturing systems to full-scale integration of humans in cyber-physical production systems. Little did we know in the 1980 s that the Operator 4.0 in the 2020 factories would resemble fighter jet-pilots, fitted with cognitive and physical enhancements and connected globally through cyber-physical systems and the Internet of Things, Services and People (IoTSP) (Romero, Wuest, Stahre, \& Gorecky, 2017).

The special issue has described a wide range of scholarly and industrial efforts that strive to enhance the productivity of a future workforce while maintaining the motivation and skill of humans on the shopfloor. Is it different this time? Will the Fourth Industrial Revolution, or Industry 4.0, forever change manufacturing jobs as we know them? Well, it is likely that the described human enhancements and cyber-physical systems integration will create radically different workplaces. It is also plausible that automation (Winroth, Säfsten, \& Stahre, 2007) and connectivity (Bärring et al., 2018) will reduce the need for many traditional tasks, while simultaneously adding much higher skill demands on many other tasks. It may even be so that the abstract anthropocentric work models suggested by e.g. Brödner (1988a,1988b) can be realised through Operator 4.0 technologies (Romero et al., 2016b), thus claiming a foreseen superior work-life. It is likely that technologies of the Fourth Industrial Revolution will suffer from the classical paradox or irony of automation, as suggested by Bainbridge (1983): "the more you automate, the more you have to rely on humans to solve unforeseen problems and anomalies that occur in any complex system". The Operator 4.0 paradigm is an attempt to enable the future workforce to handle complexity by complementing and enhancing rather than replacing human capabilities and skills.

\section{References}

Bainbridge, L (1983). Ironies of automation. Automatica, 19(6), 775-779.

Bärring, M., Lundgren, C., Åkerman, M., Johansson, B., Stahre, J., Engström, U., \& Friis, M. (2018). 5G enabled manufacturing evaluation for data-driven decision-making. 51st CIRP conference on manufacturing system, Procedia CIRP: vol. 72, (pp. 266-271).

Bortolini, M., Faccio, M., Gamberi, M., \& Pilati, F. (2018). Motion Analysis System (MAS) for production and ergonomics assessment in the manufacturing processes. Computers \& Industrial Engineering. https://doi.org/10.1016/j.cie.2018.10.046.

Boston Consulting Group (2015a). Report on "Man and Machine in Industry 4.0: How Will Technology Transform the Industrial Workforce Through 2025?".

Boston Consulting Group (2015b). Report on "Industry 4.0: The Future of Productivity and Growth in Manufacturing Industries".

Brödner, P. (1988b). Options for CIM: 'Unmanned Factory' versus Skill-based manufacturing. International Journal of Computer Integrated Manufacturing Systems, 1(2), 67-74.

Brödner, P. (1988a). Group technology - A strategy towards higher quality of working life IFAC workshop. Karksruhe, Germany: VDI/VDE-Gesellschaft Mess- und Regelungstechnik.

Cohen, Y., Naseraldin, H., Chaudhuri, A., \& Pilati, F. (2019). Assembly systems in industry 4.0 era: A road map to understand assembly 4.0. International Journal of Advanced Manufacturing Technologies. https://doi.org/10.1007/s00170-019-04203-1.

Dimirovski, G. M., Dinibütün, A. T., Kile, F., Neck, R., Stahre, J., \& Vlacic, L. B. (2006), Control system approaches for sustainable development and instability management in the globalization age. Annual Reviews in Control, 30(1), 103-115.

Fantini, P., Pizone, M., \& Taisch, M. (2018). Placing the operator at the centre of industry 4.0 design: Modelling and assessing human activities within cyber-physical systems. Computers \& Industrial Engineering. https://doi.org/10.1016/j.cie.2018.01.025.

Fletcher, S. R., Johnson, T., Adlon, T., Larreina, J., Casla, P., Parigot, L., \& Otero, M. D. M. (2019). Adaptive automation assembly: Identifying system requirements for technical efficiency and worker satisfaction. Computers \& Industrial Engineering. https://doi.org/ 10.1016/j.cie.2019.03.036.

Kaasinen, E., Schmalfuß, F., Özturk, C., Aromaa, S., Boubekeur, M., Heilala, J., ... Walter, T. (2019). Empowering and engaging industrial workers with Operator 4.0 solutions. Computers \& Industrial Engineering. https://doi.org/10.1016/j.cie.2019.01.052.

Lithoxoidou, E., Doumpoulakis, S., Tsakiris, A., Ziogou, C., Krinidis, S., Paliokas, I., ... Tzovaras, D. (2019). A novel social gamified collaboration platform enriched with shop-floor data and feedback for the improvement of the productivity, safety and engagement in factories. Computers \& Industrial Engineering. https://doi.org/10.1016/ j.cie.2019.02.005.

Matt, D. T., Orzes, G., Rauch, E., \& Dallasega, P. (2018). Urban production - A socially sustainable factory concept to overcome shortcomings of qualified workers in smart SMEs. Computers \& Industrial Engineering. https://doi.org/10.1016/j.cie.2018.08.035.

Mattsson, S., Fast-Berglund, ̊̊., Li, D., \& Thorvald, P. (2018). Forming a cognitive automation strategy for Operator 4.0 in complex assembly. Computers \& Industrial Engineering. https://doi.org/10.1016/j.cie.2018.08.011.

Peruzzini, M., Grandi, F., \& Pellicciari, M. (2018). Exploring the potential of Operator 4.0 interface and monitoring. Computers \& Industrial Engineering. https://doi.org/10. 1016/j.cie.2018.12.047.

Pinzone, M., Albè, F., Orlandelli, D., Barletta, I., Berlin, C., Johansson, B., \& Taisch, M. (2019). A framework for operative and social sustainability functionalities in humancentric cyber-physical production systems. Computers \& Industrial Engineering. https:// doi.org/10.1016/j.cie.2018.03.028.

Rauch, E., Linder, C., \& Dallasega, P. (2019). Anthropocentric perspective of production before and within industry 4.0. Computers \& Industrial Engineering. https://doi.org/10. 1016/j.cie.2019.01.018.

Romero, D., Noran, O., Stahre, J., Bernus, P., \& Fast-Berglund, Å. (2015). Towards a human-centred reference architecture for next generation balanced automation systems: Human-automation symbiosis. In S. Umeda, M. Nakano, H. Mizuyama, N. Hibino, \& D, Kiritsis, G. von Cieminski, (Eds.). Innovative production management towards sustainable growth, service, manufacturing, and resilient value chain, International Federation for Information Processing (IFIP), AICT 460, Part II (pp. 556-566). Springer.

Romero, D., Bernus, P., Noran, O., Stahre, J., \& Fast-Berglund, A. (2016a). The Operator 4.0: Human cyber-physical systems \& adaptive automation towards human-automation symbiosis work systems, production management initiatives for a sustainable world. In I. Naas, O. Vendrametto, J. Mendes, R. Goncalves, M. Terra, D. Kiritsis, \& G. Von Cieminski (Eds.). Production management initiatives for a sustainable world, International Federation for Information Processing (IFIP), AICT 488 (pp. 677-686). Springer.

Romero, D., Stahre, J., Wuest, T., Noran, O., Bernus, P., Fast-Berglund, ^̊., \& Gorecky, D. (2016b). Towards an Operator 4.0 typology: A human-centric perspective on the fourth industrial revolution technologies. International conference on computers \& industrial engineering (CIE46) proceedings, Tianjin, China. Proceedings, 29-31 October 2016, Tianjin/China (pp. 1-11).

Romero, D., Wuest, T., Stahre, J., \& Gorecky, D. (2017). Social factory architecture: Social networking services and production scenarios through the social internet of things, services and people for the social Operator 4.0. In H. Lödding, R. Riedel, K.-D. Thoben, D. Kiritsis, \& G. von Cieminski (Eds.). Shaping the future of production management - The path to intelligent, collaborative and sustainable manufacturing. International Federation for Information Processing (IFIP), AICT 513, Part I (pp. 265-273). Springer.

Segura, Á., Diez, H. V., Barandiaran, I., Arbelaiz, A., Álvarez, H., Simões, B., \& Ugarte, R. (2018). Visual computing technologies to support the Operator 4.0. Computers \& Industrial Engineering. https://doi.org/10.1016/j.cie.2018.11.060.

Stahre, J. (1995). Evaluating human/machine interaction problems in advanced manufacturing. International Journal of Computer Integrated Manufacturing Systems, 8(2), $143-150$. 
Taylor, M. P., Boxall, P., Chen, J. J. J., Xu, X., Liew, A., \& Adeniji, A. (2018). Operator 4.0 or Maker 1.0? Exploring the Implications of industrie 4.0 for innovation, safety and quality of work in small economies and enterprises. Computers \& Industrial Engineering. https://doi.org/10.1016/j.cie.2018.10.047.

Winroth, M., Säfsten, K., \& Stahre, J. (2007). Automation strategies: Existing theory or ad hoc decisions? International Journal of Manufacturing Technology and Management, 11(1), 98-114.

Zolotová, I., Papcun, P., Kajáti, E., Miškuf, E., \& Mocnej, J. (2018). Smart and cognitive solutions for Operator 4.0: Laboratory H-CPPS case studies. Computers \& Industrial Engineering. https://doi.org/10.1016/j.cie.2018.10.032.
David Romero $^{\mathrm{a}, *}$, Johan Stahre ${ }^{\mathrm{b}}$, Marco Taisch ${ }^{\mathrm{c}}$

a Tecnológico de Monterrey, Mexico

${ }^{\mathrm{b}}$ Chalmers University of Technology, Sweden

${ }^{\mathrm{c}}$ Politecnico di Milano, Italy

E-mail addresses: david.romero.diaz@gmail.com (D. Romero), johan.stahre@chalmers.se (J. Stahre), marco.taisch@polimi.it (M. Taisch).

* Corresponding author. 